\title{
Seismic monitoring of Soviet nuclear tests to resume
}

\section{Washington}

SEISMic monitoring of the Soviet nuclear test facility in Kazakhstan by a private US organization will continue for another 14 months following an agreement signed in Moscow last month, but the ground rules are to be altered. Recordings will be permitted to continue during nuclear tests, but the stations will have to move at least 600 miles from the test site, five times further than they are now.

The National Resources Defense Council (NRDC), a private non-profit environmental protection organization, first established the listening posts last summer in conjunction with the Soviet Academy of Sciences (see Nature 321, $638 ; 1986)$. The posts were intended to show that effective monitoring was no obstacle to a test-ban treaty. But when the stations were first established, the Soviet Union was observing a unilateral moratorium on nuclear testing. When tests resumed early in February, the three stations were required to shut down.

Under the new agreement signed with the Soviet Academy, the stations will be permitted to continue to operate during bomb tests, a move NRDC staff member Jacob Scherr sees as a significant shift in Soviet policy. Part of the reason for the change of heart is the existence of a USsponsored seismic station at Urumqi in northern China, about 600 miles south of the Kazakh test site. NRDC stations will be located to the north and west of the test site.

The US government has not been comfortable with the NRDC effort. State Department officials say it is not the job of private organizations to conduct US foreign policy. The United States prefers a monitoring scheme called CORRTEX (continuous reflectometry for radius versus time) that requires a bore hole 50 feet from the test chamber. The Soviet Union has shown no interest in this scheme, proposing instead that the countries explode one of their own bombs at the other's test site. International seismic stations could then be calibrated for yield determination starting with a known figure. After an initial flurry of interest, the bomb-swap scheme seems to have died quietly.

The existing monitoring stations will continue to operate for the remainder of this year, but will shut down during bomb tests. The new agreement calls for five stations, the first of which could be established as early as this November. The project's base has been moved from Karkaralinsk, Kazakhstan to Garm, Tadjikstan.

Joseph Palca

Vera Rich adds: According to Soviet sources, the US equipment will be calibrated by means of a non-nuclear (chemical) explosion in the next few weeks. The Soviet side have hailed the extended agreement as a confirmation of Soviet readiness to take part in "diverse verification undertakings", including, possibly, the establishment of an international verification system.

Meanwhile the Soviet oil industry is continuing its series of 20-kilotonne nuclear explosions in the Ural oil fields, events which, the Soviet spokesman say, have nothing in common with bomb tests, except that both kinds of explosions are nuclear and underground.

\section{Chernobyl defendants in defiant mood}

\section{London}

THE trial of the six persons accused of responsibility for the Chernobyl disaster opened in Chernobyl town last week. According to indictment, the six, during the course of a number of years, repeatedly violated operating instructions and, in particular, on the night of $25 / 26$ April 1986, whilst conducting experiments on the No. 4 generating set, "crudely violated" operating rules, thereby causing the explosion. The six were indicted under Article 220/2 of the Ukranian Criminal Code, covering breaches of safety regulations at explosion-prone enterprises.

Although only the first day of the trial was open to the media, it is clear that the accused are prepared to put up a fight. Viktor Bryukhanov, former director of the power station, says he was not on duty at the time of the accident, Mykola Fomin, former chief engineer, blames the design of the reactor and "technical shortcomings", Anatol' Dyatkov, his former assistant, blames a construction fault, and Boris Roguzhin, head of the shift on duty at the time of the accident, maintains that up to the moment of the accident, he was working according to the rule-book.

Responsibility for the accident is clearly to be confined to the on-site personnel the others are engineers Aleksandr Kovelenko and Yurii Lanshkin. A subsidiary charge against them is that immediately after the accident they gave distorted information about the radiation situation and did not take the necessary precautionary measures. If this is proved, it will make them formally responsible for the delays in evacuating the affected areas and in notifying neighbouring countries of the danger.

\section{Locust swarms threatening}

\section{London}

Huge swarms of desert locusts in the Red Sea coastal areas of Ethiopia are under attack by a few pesticide-wielding aircraft, in a desperate battle to prevent a major outbreak in northern and western Africa. But there are serious obstacles, including inadequate resources and civil strife.

"We're worried that we will get major swarms over other areas within a few months", says Lukas Brader, director of the Emergency Centre for Locust Operations of the UN Food and Agriculture Organization (FAO) in Rome.

In the past few weeks, a giant cloud of desert locusts covered many square kilometres in Eritrea, including Asmara airport. The locusts, which have found favourable breeding conditions with the return of the rains, have been moving into northern Ethiopia and eastern Sudan in ever-increasing numbers, the worst outbreak in several decades.

A control programme would have faced the best chances of success earlier this year, when the newly-hatched insects could not fly and would have been easier to kill. But the spraying programme in spring "was not as effective as we had hoped", according to the FAO's Jeremy Rossey, who blames the fact that ground teams could not safely work in the strifetorn areas of northern Ethiopia. In addition, locust control organizations have simply not been geared up for a large-scale invasion, after winding down and concentrating on other pests during the prolonged drought when locusts were not a problem. Surveying and forecasting teams were disbanded. "Complacency about locusts really set in", says one specialist.

Now, instead of a coordinated system of control, the situation has become one of "crisis management", some scientists say. But the resources are inadequate to deal with the crisis. Supplies of the pesticide fenitrothion are running low at the Desert Locust Control Organization for East Africa in Addis Ababa, and there are only three aircraft available for spraying work.

The European Economic Community has just donated 50,000 litres of the pesticide, enough for $1,500 \mathrm{~km}^{2}$, according to Rossey. Now that the swarms have moved to very rough terrain, however, spraying will be much less effective, or even impossible, as the insects shelter in ravines up to 1,000 metres deep.

The danger is that the locust swarms could move to the farming areas of the African Sahel; already, some crop damage is being reported in northern Ethiopia. The infestation may spread back to the Red Sea coast, or to the Ogaden Desert area.

Kathy Johnston 